\title{
EFFECT OF STORAGE PERIOD ON THE ACCURACY OF ELASTOMERIC IMPRESSIONS
}

\author{
Eduardo Batista FRANCOํㅜ, Leonardo Fernandes da CUNHA², Ana Raquel BENETTI ${ }^{3}$
}

\author{
1- DDS, MSc, PhD, Associate Professor, Department of Operative Dentistry, Endodontics, and Dental Materials, Bauru School of Dentistry, \\ University of São Paulo, Bauru, SP, Brazil. \\ 2- DDS, MSc, Master's degree student, Department of Operative Dentistry, Endodontics, and Dental Materials, Bauru School of Dentistry, \\ University of São Paulo, Bauru, SP, Brazil. \\ 3- DDS, MSc, PhD student, Department of Operative Dentistry, Endodontics, and Dental Materials, Bauru School of Dentistry, University of \\ São Paulo.
}

Corresponding address: Eduardo Batista Franco (ebfranco@fob.usp.br) - Departamento de Dentística - Faculdade de Odontologia de Bauru - Al. Octávio Pinheiro Brisolla, 9-75 - Vila Universitária, Bauru, SP, Brasil 17012-901 - Phone: 5514 3235-8484 - Fax: $55143235-8523$

Received: October 25, 2006 - Modification: March 09, 2007 - Accepted: April 18, 2007

\begin{abstract}
A

ims: To investigate the effect of the storage period on the accuracy of recently developed elastomeric materials. Methods: Simultaneous impressions of a steel die were taken using a polyether (I: Impregum Soft Heavy and Light body, 3M ESPE) and vinyl polysiloxane (P: Perfectim Blue Velvet and Flexi-Velvet, J.Morita). The trays were loaded with the heavy-bodied impression materials while the light-bodied impression materials were simultaneously spread on the steel die. The impressions were poured after 2 hours, 24 hours, and 7 days. Impressions were stored at approximately 55\% relative humidity and room temperature. Ten replicas were produced for each experimental condition $(n=60)$. Accuracy of the stone dies was assessed with a depthmeasuring microscope. The difference in height between the surface of the stone die and a standard metallic ring was recorded in micrometers at four demarcated points, by two independent examiners. Data were submitted to two-way ANOVA and Tukey test $(\alpha=0.05)$. Results: Significant differences were found among the groups. Smaller discrepancies were observed when pouring was performed up to 24 hours ( $\mathrm{I}-2 \mathrm{~h}=65.0 \pm 15.68 \mu \mathrm{m}$; I-24h= $81.6 \pm 11.13 \mu \mathrm{m}$ ) for the polyether, and up to 7 days for the vinyl polysiloxane $(\mathrm{P}-2 \mathrm{~h}=79.1 \pm 13.82 \mu \mathrm{m} ; \mathrm{P}-24 \mathrm{~h}=96.8 \pm 6.02 \mu \mathrm{m} ; \mathrm{P}-7 \mathrm{~d}=81.4 \pm 4.3 \mu \mathrm{m})$. Significant dimensional discrepancies, however, were observed when polyether was stored for 7 days $(I-7 d=295.3 \pm 17.4 \mu \mathrm{m})$. Conclusion: Storage may significantly affect the dimensional accuracy of impressions and, thus, a maximum period and storage condition should be specified for the recently developed materials.
\end{abstract}

Uniterms: Dental impression materials; Vinyl polysiloxane; Polyether.

\section{INTRODUCTION}

Dimensional stability of impression materials has been widely discussed in the dental literature ${ }^{6}$. The dimensional stability depends directly on the elastic recovery of the material, shrinkage of the impression material, evaporation of volatile components from the impression material, or expansion of the gypsum ${ }^{4,13}$.

Polyethers and vinyl polysiloxanes are suggested to be more dimensionally stable than polysulfides and condensation silicones ${ }^{1,7}$. Due to their dimensional stability, polyethers and vinyl polysiloxanes quickly became very popular materials for dental impressions. However, their stability depends also on the exact moment of pouring stone dies, in order to minimize distortion of the impressions. While one may consider that the delay in pouring is not a critical factor for polyethers and vinyl polysiloxanes ${ }^{1}$, dimensional changes have been previously reported as a variation of consistencies among products of the same type $e^{6,9}$. For example, contrary results have reported that polyether undergoes very little dimensional changes within 24 hours after impression ${ }^{19}$ or that it will produce inaccurate dies after the same delay period ${ }^{16}$. Another study found that polyether suffers little dimensional changes even after 7 days of storage $^{15}$. Different investigations have shown that the accuracy of polyethers may be significantly affected depending on the storage time and humidity ${ }^{9,14}$.

Therefore, deciding on the exact moment of pouring stone dies is an important step during the fabrication of dental prostheses. A delay in pouring will allow the material to recover elastically after being separated from the retentive areas of the mouth ${ }^{8,11}$. Additionally, a delay may be necessary to permit the release of by-products that can influence the accuracy of the stone dies ${ }^{1,14,18}$. Polysulfides, for example, 
release water whereas condensation silicones release alcohol during the polymerization reaction ${ }^{1,7}$. It has also been observed that some vinyl polysiloxanes may release hydrogen as a secondary reaction of the residual hydrates of the polymer ${ }^{18}$. It has been observed that polyethers can release volatile substances as well, or yet absorb water ${ }^{9,14}$. Therefore, although the delay period should allow both the release of volatile substances and the elastic recovery of the material, it should not be too long, otherwise distortions in the impression will occur.

Nonetheless, most studies addressing the dimensional stability of impression materials were conducted in the 1970's and 1980's. Despite this, new materials have been constantly developed and subjected to continuous modifications, which may reflect on the materials' properties. Among such newly formulated materials, polyethers and vinyl polysiloxanes are mainly on focus. Modifications in the materials' formulations to achieve a different degree of stiffness or viscosity of the materials have been introduced with the aim of improving the impression technique, but these modifications do not guarantee maintenance of their properties. Therefore, it is important to evaluate the dimensional stability of recently developed materials. The aim of this study was to investigate the effect of the storage period of elastomeric impressions on the dimensional accuracy of stone dies, considering that the development of new formulations does not predict the dimensional stability of their predecessors. The null hypothesis was that no differences were to be observed among either different storage periods or different materials.

\section{MATERIALAND METHODS}

The materials used in this study were a polyether (Impregum Soft; 3M ESPE, Seefeld, Germany) and a vinyl polysiloxane (Perfectim; J. Morita USA Inc, Irvine, CA, USA). In order to obtain the impressions, a stainless steel die simulating a full crown preparation (8 mm cervical diameter; $6 \mathrm{~mm}$ occlusal diameter; $8 \mathrm{~mm}$ height) was used. A mark in the occlusal surface of the steel die guided the adaptation of a metallic ring, leveled at zero. The method used in this study (Figure 1) is in accordance with the one described by de Araújo \& Jørgensen².

Perforated acrylic cylindrical trays (12 mm diameter) were attached to the lower part of the device. The steel die, attached to the upper part of the stand, was centralized in the acrylic tray to obtain impressions with a material thickness of approximately $2 \mathrm{~mm}$. This measurement was obtained from the distance between the tray and the gingival preparation margin of the steel die. A distance of $2 \mathrm{~mm}$ between the top surface of the preparation and the depth of the tray was maintained.

The impression materials were mixed according to the manufacturer's instructions at controlled temperature (22 \pm $\left.1^{\circ} \mathrm{C}\right)$ and humidity (55 $\pm 5 \%$ ) conditions. Proportion of the materials was established by weight in a precision scale. Mixing was accomplished on a glass plate with a metallic spatula to obtain a homogeneous mixture within 30 seconds.

The simultaneous double-mix technique was adopted for all impressions, thus heavy-bodied impression materials [Impregum Soft Heavy Body (ISH), 3M ESPE; Perfectim Blue Velvet (PBV), J. Morita] were combined with light-bodied impression materials [Impregum Soft Light Body (ISL), 3M ESPE; Perfectim Flexi Velvet (PFV), J. Morita] from the same manufacturer. For this technique, the trays were loaded with the heavy-bodied material (ISH or PBV) while the lightbodied material (ISL or PFV) was simultaneously spread on the steel die. The impressions were separated from the preparation with axial movement after 10 minutes and stored at approximately 55\% relative humidity and room temperature for 2 hours, 24 hours and 7 days. Then, improved die stone type IV (Durone, Dentsply, Petrópolis, RJ, Brazil) in a 0.19 water-to-powder ratio was mixed and poured into the impression under mechanical vibration. Ten dies were produced for each of the 6 experimental conditions $(n=60)$.

After 2 hours, the stone die was separated from the impression and transferred to a stand in a depth-measuring microscope (Carl Zeiss Depth Measuring Microscope 4987926; Zeiss, Jena, Germany). Fitting of the metallic ring to the dies determined the dimensional accuracy of the specimens when compared to the standard steel die. The opening on the occlusal surface of the metallic ring and the demarcations made on its margins standardized its insertion in the steel die and in the stone dies, under a constant load of $250 \mathrm{~g}$. The occlusal surface of the metallic ring and the steel die were leveled at zero, which was considered the referential for the measurements obtained in the measuring microscope.

The metallic ring and die were perpendicularly positioned under the objective of the depth-measuring microscope at 160x magnification. First, focus was determined on the

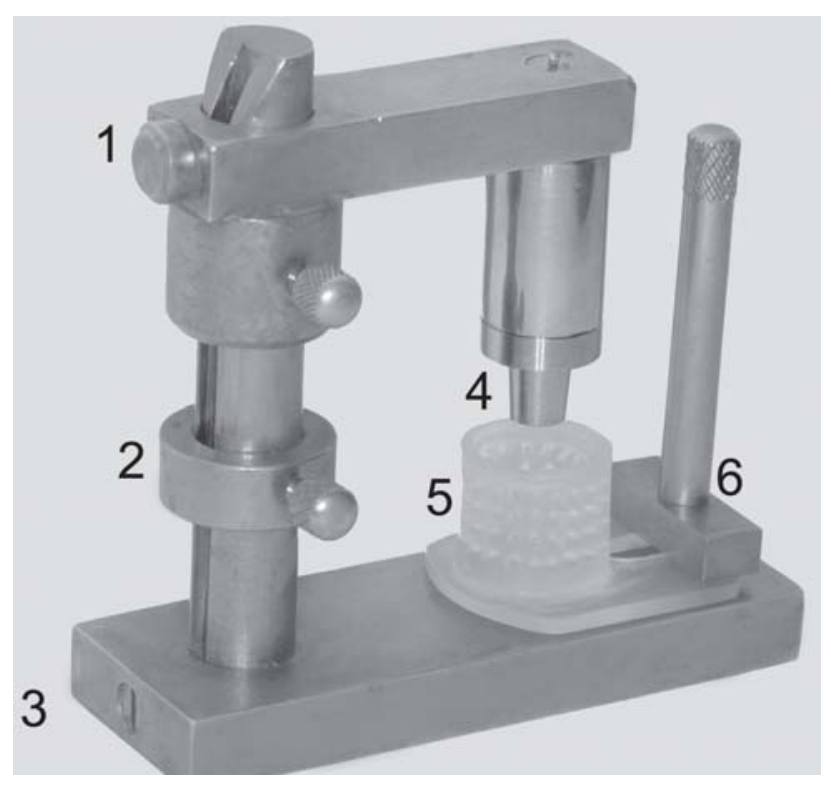

FIGURE 1- Apparatus used to take the impressions: 1) the upper part slides on the vertical axis of the base until it reaches a stop (2); 3) base of the apparatus; 4) steel die; 5) perforated acrylic impression tray fixed at the base of the apparatus with a metallic screw and bar (6) 
occlusal surface of the metallic ring and the microscope was set at zero. Then focus was determined at the occlusal surface of the stone die. The difference in height between the surface of the stone die and the ring was recorded in micrometers. Four measurements were made on each specimen at different points by two independent examiners. Data were submitted to two-way analysis of variance and Tukey's multiple comparison test $(\alpha=0.05)$.

\section{RESULTS}

All replicas resulted in positive discrepancies for both polyether and vinyl polysiloxane, which indicated that all replicas were slightly larger than the standard steel die for all evaluation periods.

Logarithmically transformed data were submitted to twoway analysis of variance. Significant differences between materials, periods of storage of the impressions, and interaction were detected for both tested materials $(p<0.0001)$. Tukey's test $(\alpha=0.05)$ confirmed smaller discrepancies when pouring was performed up to 2 hours after impression, regardless of the material. Slightly greater discrepancies of the stone dies were observed when the storage of both polyether and vinyl polysiloxane was increased to 24 hours. Significantly greater discrepancies were observed for the polyether when impressions were stored for 7 days, while the vinyl polysiloxane remained as stable as it was at the 2-hour period (Table 1).

\section{DISCUSSION}

Considering the material itself, polyethers and vinyl polysiloxanes are expected to result in higher dimensional stability. The discrepancies detected for these materials may result, among other reasons, from the incomplete elastic recovery ${ }^{6}$ or from the residual polymerization, resulting in shrinkage of the impression. During polymerization, new covalent bonds are formed within the molecules, reducing the volume occupied by them ${ }^{1,3,11}$. Thus, the shrinkage resulting from material polymerization will contribute to the loss of accuracy over time ${ }^{5,11}$. This could be confirmed for both vinyl polysiloxane and polyether materials used in this study.

The storage of impressions, however, is somehow controversial. According to the manufacturers, both polyether and vinyl polysiloxane impressions may be stored for up to 14 days prior to pouring of the dies without compromising the accuracy of the material. However, in the present study, polyether and vinyl polysiloxane impressions could be stored without detrimental effects for up to 24 hours and 7 days, respectively. It should be noted that significant dimensional discrepancies were observed when the polyether impressions were stored for 7 days. Marcinak, et al. ${ }^{16}$ (1980) had already found discrepancies in dies obtained from polyether impressions stored for 24 hours. Another study detected that heavy-bodied polyethers may result in enlarged or smaller replicas when compared to the original preparations depending on the storage time and humidity ${ }^{14}$.

Although a small difference was found for the polyether impressions stored between 2 and 24 hours, significantly greater discrepancies were detected after storage for 7 days. It is known that polyether is a highly hydrophilic material and absorbs water from the surrounding atmosphere in vapor saturated environments, thus resulting in smaller dies $^{9,14}$. The time of the year, heating of the storage room and location might influence the relative humidity of the environment ${ }^{9}$. The storage humidity is especially relevant for the polyether when the stone dies are poured after 24 hours and the impressions are stored in highly humid environments $^{9,14}$. In this study, however, the impressions were stored in approximately 55\% relative humidity.

It seems that polyether also releases volatile substances. The smell of even well cured Impregum may be an indicator for this assumption ${ }^{14}$. Therefore, it is more likely that the enlargement observed in the replicas submitted to longer storage periods is supposedly related to the evaporation of volatile compounds. This has been previously suggested by Endo and Finger ${ }^{9}$ (2006) and Kanehira, et al. ${ }^{14}$ (2006). Because, polyether is susceptible to either release of volatile substances or water uptake, pouring of dies should preferably be performed within 24 hours after impression, which is advised from the data obtained in this study and from other studies ${ }^{9,14}$.

Vinyl polysiloxane, on the other hand, is predominantly hydrophobic and does not absorb water during the storage period. This probably explains the little dimensional alteration of this material in this study, as previously observed ${ }^{9,14}$.

Given that several factors affect the accuracy of impressions, variability within specimens is expected. The high standard deviation observed in this study confirms the outcomes of previous investigations on impression

TABLE 1- Means and standard deviation of the discrepancies of stone dies obtained after different storage periods of impressions. Homogeneous grouping was determined by Tukey's multiple comparison test $(\alpha=0.05)$

\begin{tabular}{llll} 
Material & $\mathbf{2}$ hours & $\mathbf{2 4}$ hours & $\mathbf{7}$ Days \\
\hline Polyether (Impregum, 3M ESPE) & $65.0 \pm 15.68 \mathrm{a}, \mathrm{A}$ & $81.6 \pm 11.13 \mathrm{a}, \mathrm{B}$ & $295.3 \pm 17.40 \mathrm{a}, \mathrm{C}$ \\
Vinyl polysiloxane (Perfectim, J. Morita) & $79.1 \pm 13.82 \mathrm{a}, \mathrm{A}$ & $96.8 \pm 6.02 \mathrm{a}, \mathrm{B}$ & $81.4 \pm 4.30 \mathrm{~b}, \mathrm{AB}$ \\
\hline
\end{tabular}

Means followed by the same lowercase letters in columns and uppercase letters in lines indicate no statistically significant difference at $95 \%$ confidence level. 
materials ${ }^{4,10-12}$. The use of different consistencies, heavy and light, may have been responsible for such result due to the effect of different dimensional changes among them. The heavy-bodied material is likely to produce less discrepancies in comparison to the light-bodied material because it contains higher concentration of fillers ${ }^{6,17}$. When the one-step double impression technique is used, like in the present study, the layer of the light-bodied material material is usually thin, and consequently it has an insignificant influence on the accuracy of the impression ${ }^{9}$.

Although the new formulations of impression materials proposed by the manufacturers have an overall positive influence on their properties, the storage period and conditions should be better defined in their instructions for use. It is, therefore, important that clinicians be aware of the factors affecting the accuracy of the impression materials that they currently adopt, in order to optimize the clinical results.

\section{CONCLUSIONS}

Prolonged storage may significantly affect the dimensional accuracy of polyether impressions, thus rejecting the null hypotesis. Therefore, the maximum period and storage condition should be specified for the recently developed materials.

\section{REFERENCES}

1- Anusavice KJ. Materiais de moldagem elastoméricos não aquosos. In: Anusavice KJ. Materiais dentários. Rio de Janeiro: Guanabara Koogan; 1998. p. 83-106.

2- Araújo PA, Jørgensen KD. Effect of material bulk and undercuts on the accuracy of impression materials. J Prosthet Dent. 1985;54(6):791-4.

3- Bailey WJ, Iwama H, Tsushima R. Synthesis of elastomers by cationic polymerization with expansion in volume. J Polym Sci. 1976;56:117-27.

4- Cayouette MJ, Burgees JO, Jones RE, Yuan CH. Three-dimensional analysis of dual-arch impression trays. Quintessence Int. 2003;34(3):189-98.

5- Craig RG. A review of properties of rubber impression materials. J Mich Dent Assoc. 1977;59:254-61.

6- Craig RG. Review of dental impression materials. Adv Dent Res. 1988;2(1):51-64.

7- Eames WB, Wallace SW, Suway NB, Rogers LB. Accuracy and dimensional stability of elastomeric impression materials. J Prosthet Dent. 1979;42(2):159-62.

8- Endo T, Finger WJ. Evaluation of the elastic recovery of polyether impression materials. Am J Dent. 2005;18(6):355-60.

9- Endo T, Finger WJ. Dimensional accuracy of a new polyether impression material. Quintessence Int. 2006;37(1):47-51.
10- Fenske C. The influence of five impression techniques on the dimensional accuracy of master models. Braz Dent J. 2000;11(1);1927.

11-Franco EB. Influência do reembasamento de moldes no comportamento mofodimensional de troquéis obtidos a partir de diferentes materiais elastoméricos [tese]. Bauru: Universidade de São Paulo, Faculdade de Odontologia de Bauru; 1998.

12- Fusayama T, Iwaku M, Daito K, Kurosaki N, Takatsu T. Accuracy of the laminated single impression technique with silicone materials. J Prosthet Dent. 1974;32(3):270-6.

13- Jørgensen KD. Thermal expansion of addition polymerization (type II) silicone impression materials. Aust Dent J. 1982;27(6):37781.

14- Kanehira M, Finger WJ, Endo T. Volatilization of components from and water absorption of polyether impressions. J Dent. 2006;34(2):134-8.

15- Luebke RJ, Scandrett FR, Kerber PE. The effect of delayed and second pours on elastomeric impression material accuracy. J Prosthet Dent. 1979;41(5):517-21.

16- Marcinak CF, Young FA, Draughn RA, Flemming WR. Linear dimensional changes in elastic impression materials. J Dent Res. 1980;59(7):1152-5.

17- McCabe JF, Storer R. Elastomeric impression materials: the measurement of some properties relevant to clinical practice. $\mathrm{Br}$ Dent J. 1980;149(3):73-9.

18- Mc Crosson J, Sharkey SW, Smith GM, Anderson RA. Quantification of hydrogen gas released from polyvinylsiloxane impression materials in contact with die stone materials. J Dent. 1987;15(3):129-32

19- Williams PT, Jackson DG, Bergman W. An evaluation of the time-dependent dimensional stability of eleven elastomeric impression materials. J Prosthet Dent. 1984;52(1):120-5. 